\title{
Stimulation of fibroblast proliferation by thrombospondin
}

\author{
Sem H. Phan, Rene G. Dillon, Bridget M. $\mathbf{M}^{\mathfrak{c}}$ Garry and Vishva M. Dixit
}

Department of Pathology, University of Michigan, Ann Arbor, MI

Received July 10, 1989

Thrombospondin purified from human platelets was examined for its ability to promote proliferation of human dermal fibroblasts. The results show that thrombospondin could stimulate the incorporation of $\left[{ }^{3} \mathrm{H}\right]$ thymidine by quiescent fibroblasts in a dose-dependent manner without stimulating protein or collagen synthesis. The effect was observed even in the total absence of serum, although the degree of stimulation was substantially lower than that in the presence of $0.4 \%$ fetal calf serum, but higher than that in the presence of $4 \%$ serum. The effect was specific and not due to contaminants as demonstrated by the ability of antibodies to thrombospondin to specifically inhibit this stimulation. Three monoclonal antibodies directed at different epitopes in the thrombospondin molecule were equally effective in inhibiting this effect. This stimulation of fibroblast proliferation by thrombospondin suggests a potential role for this matrix protein in the mesenchymal cell response in tissue injury and repair. 1989 Academic Press, Inc.

Thrombospondin is a large glycoprotein with an estimated molecular weight of 450,000 composed of three disulfide-linked subunits, each with a molecular weight of 160,000 (1-3). Originally discovered in $\alpha$ granules of platelets, it was thought to play some role in platelet aggregation (4). Since then however, it has been abundantly found in association with the extracellular matrix of tissues and cells in culture (5-8). Furthermore, a large and increasing number of cells synthesize this molecule $(5,6,9-14)$. Because of its close association with the extracellular matrix, its role in cell adhesion, spreading and movement has been extensively investigated, and has been found to promote all three functions $(6,15-19)$. Since the extracellular matrix also influences cell proliferation, the effect of thrombospondin on this cellular functions is of interest. Studies using vascular smooth muscle cells show that thrombospondin can promote cell proliferation upon binding to the cell surface $(6,20-22)$. In conjunction with the demonstration of the increased presence of thrombospondin in the extracellular matrix of actively dividing cells relative to that of quiescent cells $(8,23)$, these findings suggest a role for thrombospondin in the cell proliferative response in tissue repair. This possibility is consistent with a recent demonstration that thrombospondin is present in increased amounts at perivascular regions of wound healing sites (8). Despite these intriguing studies however, it has not been established that other mesenchymal cells generally considered to be critical elements of the reparative process, would respond in a similar manner to thrombospondin. In this report the effects of thrombospondin on the prototypical mesenchymal cell, the fibroblast are described. The results show that thrombospondin can stimulate fibroblast proliferation, and that the effect appears not to be dependent on or mediated by increases in bulk protein and matrix synthesis. 


\section{MATERIALS AND METHODS}

Materials: All tissue culture media and reagents were obtained from Grand Island Biological Co. (Grand Island, NY). [Methyl $\left.{ }^{3} \mathrm{H}\right]$ thymidine $(6.7 \mathrm{Ci} / \mathrm{mmole}$ ) was from New England Nuclear (Boston, MA). Bacterial collagenase (CLSPA grade) for collagen synthesis assays was obtained from Cooper Biochemicals (Freehold, NJ), and purified by gel filtration as previously described (24). All other chemicals, unless otherwise specified, were of reagent grade or better.

Cells: Human dermal fibroblasts were isolated from neonatal foreskin specimens by mincing and trypsinization. The cells were subcultured in Dulbecco's modified Eagle's media containing $10 \%$ fetal calf serum and $1 \%$ antibiotics (penicillin, streptomycin and fungizone). Cells were maintained by passaging with a 1:3 split ratio upon confluence, and used only in the third to ninth passages.

Thrombospondin and antibodies: Thrombospondin was isolated from supernatants of thrombin-stimulated human platelets under calcium-replete conditions by sequential affinity chromatography on gelatin-Sepharose 4B and heparin-Sepharose 4B (both from Pharmacia, Uppsala, Sweden), followed by gel filtration chromatography on BioGel A-0.5m (Bio-Rad Laboratories, Richmond, CA) as reported previously (25). Polyacrylamide gel electrophoresis in the presence of sodium dodecyl sulfate and under reducing conditions revealed a single band migrating with an estimated molecular weight of 180,000 . Both monoclonal and polyclonal antibodies to thrombospondin were used in this study. Three monoclonal antibodies, A6.1, A2.5 and D4.6 directed to the trypsin-resistant $70 \mathrm{kD}$ core, the heparin-binding domain and a $50 \mathrm{kD}$ fragment containing the fibrinogen-binding domain (26-28), respectively, of the thrombospondin molecule were used for these studies. These antibodies were produced and characterized as previously described (26-28). Final purification was by affinity chromatography on protein A-Sepharose. Polyclonal antibody was induced in rabbits and the IgG fraction purified as previously described (26-28). Mouse myeloma IgG 1 isolated from ascites fluid and purified rabbit IgG (Sigma Chemical Co., St. Louis, MO) were used as nonspecific or nonimmune control antibodies for the monoclonal and polyconal antibodies to thrombospondin, respectively.

Cell proliferation assay: Fibroblast proliferation was assayed essentially as previously described (29). Cells were plated on 96-well flat-bottomed tissue culture plates and then made quiescent by incubating in serum free media. They were then exposed to the indicated concentrations of serum, thrombospondin and specified antibody and pulsed for the last 6 hours with $1 \mu \mathrm{Ci}$ of $\left[{ }^{3} \mathrm{H}\right]$ thymidine/well. Cells were harvested and processed for radioactive counting as previously described (29). Results were obtained as dpm incorporated per well, and finally expressed as \% of mean control dpm incorporated by untreated (i.e. no added thrombospondin) wells. Each experimental group was done at least in triplicate.

Protein and collagen synthesis: This was undertaken as previously described by measuring the rate of $\left[{ }^{3} \mathrm{H}\right]$ proline incorporation into purified bacterial collagenase sensitive (collagenous) and insensitive (noncollagenous) proteins by confluent human dermal fibroblasts (24, 30). Cells were exposed to the indicated concentrations of thrombospondin and then pulsed with radioactive proline for 6 hours and then analysed as described $(24,30)$.

\section{RESULTS}

Effects on cell proliferation: Addition of thrombospondin to fibroblasts made quiescent by serum deprivation caused a dose-dependent increase in [ ${ }^{3} \mathrm{H}$ thymidine incorporation beginning at a dose of $10^{-10} \mathrm{M}$ up to $10^{-7} \mathrm{M}$ (Fig. 1). Doses of thrombospondin less than $10^{-10} \mathrm{M}$ failed to significantly stimulate proliferation. Stimulation was observed even in the total absence of serum, although the percentage increase above untreated cells was smaller than that in the presence of $0.4 \%$ serum at each dose of thrombospondin examined (Fig. 1). Stimulation in the presence of $4 \%$ serum was less on a percentage basis compared to that in $0.4 \%$ serum or in the total absence of serum. However when the data were expressed in terms of the amount of dpm incorporated above that of their respective untreated controls, the effect of thrombospondin was greatest with the highest concentration of serum (Table I). In each dose in which the amount incorporated was significantly above that of the untreated mean control value, the dpm incorporated was larger than 


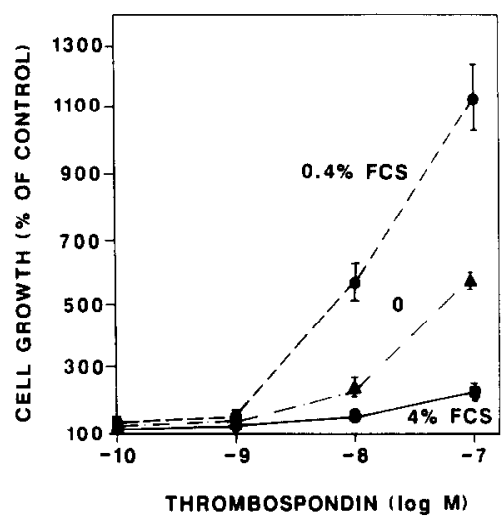

Firure 1. Effect of thrombospondin on fibroblast proliferation. Data were obtained as dpm $\left[{ }^{3} \mathrm{H}\right]$ thymidine incorporated per well and normalized as a percentage of the mean dpm incorporated by their respective (i.e. in the indicated concentration of serum, with 0 indicating serum free media) control untreated cells. Control mean values are shown in the footnotes to Table I. Results were expressed as means $\pm \mathrm{SE}$, with $\mathrm{N}=6$.

the sum of the dpm incorporated by cells treated in the absence of serum and that by untreated cells with the indicated concentration of serum. For instance, a simple additive effect of $0.4 \%$ serum (1601 \pm 106 ) and $10^{-8} \mathrm{M}$ thrombospondin (i.e. in $0 \%$ serum, $2744 \pm 370$ ) would predict a total of 4345 $\mathrm{dpm}$ being incorporated by cells exposed to $10^{-8} \mathrm{M}$ thrombospondin in $0.4 \%$ serum. The actual result however was $9060 \pm 915$ (Table I), which was more than twice the predicted value. Thus, there was a synergistic effect between thrombospondin and serum factor(s) on fibroblast proliferation. This synergism was also observed at a higher concentration of serum (4\%), although the actual stimulation was less than two-fold the corresponding predicted additive value. This was

TABLE I. Effect of thrombospondin on fibroblast proliferation: expressed as increased dpm incorporated above control

\begin{tabular}{|c|c|c|c|}
\hline \multirow[b]{2}{*}{ Treatment } & \multicolumn{3}{|c|}{ Cell Proliferation ${ }^{*}(\mathrm{dpm})$} \\
\hline & Assayed in: 0\%serum & $0.4 \%$ serum & 4\%serum \\
\hline $\begin{array}{l}10^{-7} \mathrm{M}^{-8} \mathrm{TSP}^{* *} \\
10^{-8} \mathrm{M} \text { TSP } \\
10^{-0} \mathrm{M} \text { TSP } \\
10^{-1} \mathrm{O} \mathrm{M} \text { TSP } \\
10^{-1} 1 \mathrm{M} \text { TSP } \\
10^{-1}{ }^{2} \mathrm{M} \text { TSP }\end{array}$ & $\begin{array}{c}5221 \pm 179 \\
1563 \pm 211 \\
144 \pm 15 \\
48 \pm 5 \\
\text { ND } \\
\text { ND }\end{array}$ & $\begin{array}{c}16607 \pm 1495 \\
7459 \pm 753 \\
804 \pm 67 \\
519 \pm 44 \\
461 \pm 49 \\
308 \pm 19\end{array}$ & $\begin{array}{c}27181 \pm 2771 \\
11427 \pm 666 \\
4842 \pm 120 \\
3162 \pm 168 \\
661 \pm 35 \\
581 \pm 32\end{array}$ \\
\hline
\end{tabular}

* Cell proliferation assay was performed as described in Methods. The mean dpm incorporated by untreated control cells in the presence of the indicated concentrations of serum $(1181 \pm 179,1601 \pm 106$ and $20977 \pm 320$ in $0 \%, 0.4 \%$ and $4 \%$ serum, respectively) were subtracted from that incorporated by cells treated with the indicated concentrations of thrombospondin (TSP) in the presence of the corresponding concentration of serum. The results were expressed as means $\pm \mathrm{SE}$, with $\mathrm{N}=6$.

\section{** Thrombospondin \\ ${ }^{\dagger}$ Not determined.}


probably due to a loss of linearity in the assay method as the upper limit of the amount of dpm that could be incorporated was approached. Direct examination of cell counts also revealed the stimulation of cell proliferation by thrombospondin. $1.25 \times 10^{5}$ cells were plated in $35 \mathrm{~mm}$ diameter tissue culture dishes, and cultured in the presence of the indicated concentration of thrombospondin. At the indicated times they were trypsinized and manually counted using a hemocytometer. In the presence of $4 \%$ serum, addition of $1 \mathrm{nM}$ thrombospondin caused cell number to increase at 72 hours to $4.25 \pm 0.5 \times 10^{5}$ (mean $\pm \mathrm{SE}, \mathrm{N}=4$ ) versus $2.56 \pm 0.4 \times{ }^{5}$ (mean $\pm \mathrm{SE}, \mathrm{N}=8$ ) for untreated cells ran in parallel.

Effects of antibodies: Specific antibodies were used to test for the specificity of this thrombospondin-induced stimulation of cell proliferation. Addition of polyclonal antibody significantly inhibited thymidine incorporation in $4 \%$ serum with or without added thrombospondin (Fig. 2), while nonimmune rabbit IgG had no significant effect. Similar results were obtained when the study was done in the absence of serum. Thus $50 \mu \mathrm{g} / \mathrm{ml}$ of polyclonal antibody to thrombospondin reduced thymidine incorporation of cells stimulated with $10 \mathrm{nM}$ thrombospondin from $308 \pm 14.2 \%$ to $106 \pm 7.1 \%$ of the untreated control mean. When three monoclonal antibodies (A6.1, A2.5, and D4.6) to thrombospondin were tested, similar inhibition of fibroblast proliferation was observed. Figure 3 shows the inhibitory effect of monoclonal antibody A2.5, directed at the heparin-binding domain of thrombospondin, on thymidine incorporation by cells in $4 \%$ serum with or without added thrombospondin. Nonspecific murine IgG ${ }_{1}$ did not affect proliferation significantly. Specific inhibition by monoclonal antibodies A6.1 and D4.6 of similar magnitude was also observed (data not shown). Reduction in thymidine incorporation as a result of

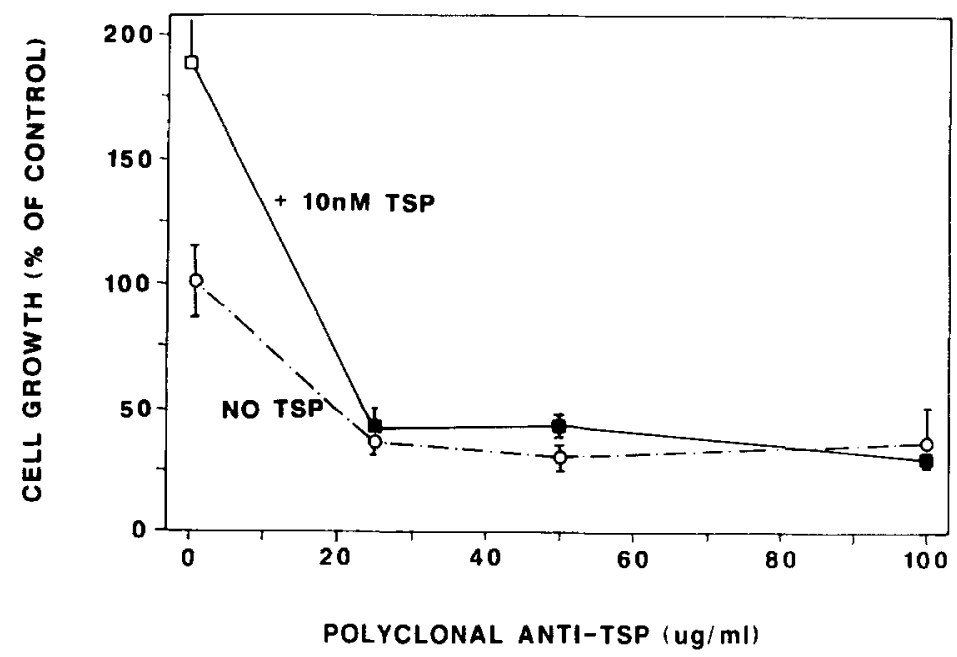

Fixure 2. Effect of polyclonal antibody to thrombospondin on proliferation. Cell proliferation was measured in the presence of $4 \%$ serum and the indicated concentration of added purified thrombospondin (TSP). Results were expressed as a percentage of the mean dpm incorporated by control untreated (no antibody or thrombospondin added) cells $(20977 \pm 320 \mathrm{dpm}$ ). Nonimmune rabbit IgG $(60 \mu \mathrm{g} / \mathrm{ml})$ had no significant effect $(108 \% \pm 19$ and $211 \% \pm 30$ for control and thrombospondin-treated, respectively). 


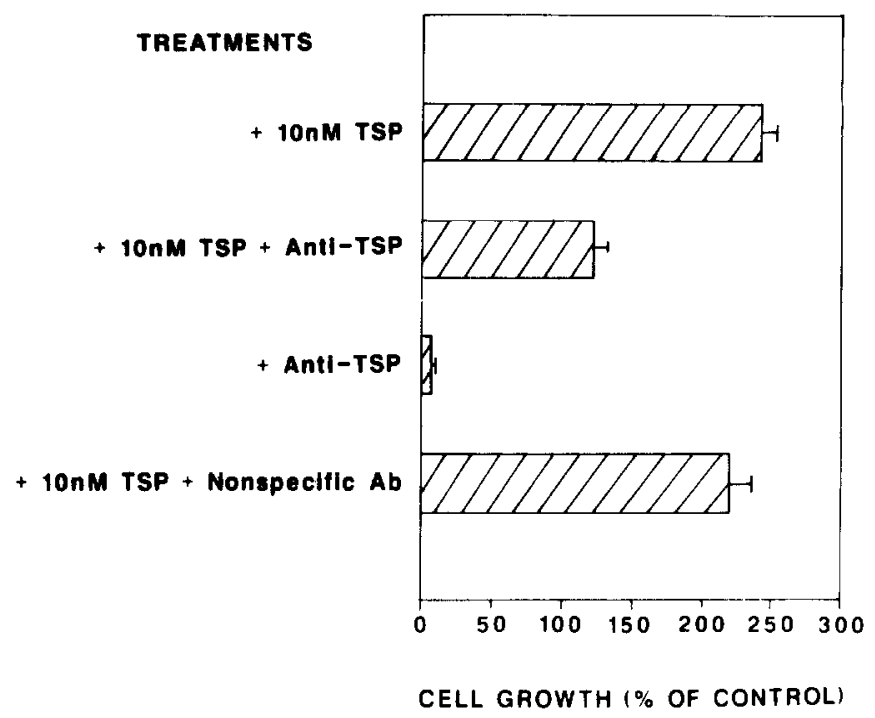

Firure 3. Effect of monoclonal antibody to thrombospondin on proliferation. Experimental design and expression of results were as described in the legend to figure 2, except $50 \mu \mathrm{g} / \mathrm{ml}$ of monoclonal antibody A2.5 was substituted for the polyclonal antibody.

anti-thrombospondin antibody treatment was not due to reduction in cell number as a result of cell detachment induced by the antibody, since direct cell counting of representative wells failed to show any significant loss in cell number as a result of antibody treatment.

Effects on protein synthesis: In view of its ability to regulate matrix-related cell functions, the effect of thrombospondin on protein, and specifically, collagen synthesis was examined, since the effects on cell movement, adhesion and growth could be indirectly mediated by alterations in matrix production. Addition of thrombospondin to fibroblasts appeared to stimulate both collagen and noncollagenous protein synthesis in a dose dependent manner, when the results were expressed as proline incorporation per well over a six hour pulse period. However when the results were corrected for cell number per well, the degree of stimulation was statistically insignificant (Tabie II). Thus the apparent stimulation observed was the result of more cells incorporating more proline as a result of the growth stimulatory properties of the exogenously added thrombospondin,

TABLE I. Effect of thrombospondin on protein synthesis

\begin{tabular}{ccc}
\hline & \multicolumn{2}{c}{ Protein Synthesis (dpm/10 ${ }^{5}$ cells) } \\
\cline { 2 - 3 } Thrombospondin $(\mathrm{M})$ & Collagenous & Noncollagenous \\
\hline 0 & & $15490 \pm 4414$ \\
$10^{-11}$ & $21994 \pm 6415$ & $10984 \pm 1816$ \\
$10^{-10}$ & $26820 \pm 3098$ & $11001 \pm 1859$ \\
$10^{-9}$ & $24497 \pm 3266$ & $12839 \pm 2808$ \\
$10^{-8}$ & $24547 \pm 3306$ & $14761 \pm 2653$
\end{tabular}

*Protein synthesis expressed as dpm of $\left[{ }^{3} \mathrm{H}\right]$ proline incorporated per well normalized to $10^{5}$ cells. The results were listed as meanst $\mathrm{SE}$, with $\mathrm{N}=4$. The mean values of all thrombospondin-treated groups were not significantly different from the mean value of the control, untreated group. 
but resulting in no net increase in protein synthesis on a per cell basis. Similarly negative results were obtained when the assays were done in the presence of $0.4 \%$ or $4 \%$ serum with $10^{-10}-10^{-8} \mathrm{M}$ thrombospondin (data not shown).

\section{DISCUSSION}

Recently binding sites for thrombospondin have been described in fibroblasts (31), which in conjunction with the increased presence of thrombospondin at sites of wound healing (8) suggests its potential role in tissue repair and fibrotic processes. The results of this study demonstrated the growth stimulatory properties of thrombospondin in human dermal fibroblasts. The stimulation was observed in the total absence of serum, thus suggesting that either thrombospondin has both competence and progression activities, or that it could induce the secretion of complementary growth factor(s) which could then in conjunction with the added thrombospondin allow cell proliferation to proceed. The addition of serum amplified the stimulation by thrombospondin in a synergistic manner. These effects on human fibroblasts are similar to those observed in rat aortic smooth muscle cells (20), although in that study purified epidermal growth factor, instead of serum, was used and found to synergistically stimulate mitogenesis in the presence of thrombospondin. The effect on smooth muscle cells is found to be specific for epidermal growth factor, and not seen with other progression growth factors such as insulin or insulin-like growth factor I (20). In the current study, it is likely that epidermal growth factor present in serum is partly responsible for the synergistic effect of serum with thrombospondin on fibroblast thymidine incorporation, although the possibility that other serum factors may contribute to the synergism cannot be excluded at this time. An added possibility is that platelet-derived growth factor in serum could stimulate endogenous thrombospondin production, as has been reported in smooth muscle and other cells $(6,32,33)$, and result in autocrine stimulation of cell proliferation. This possibility is strengthened by the antibody studies which showed that serum-dependent cell proliferation could be inhibited by anti-thrombospondin antibodies.

As expected, this growth stimulatory effect of thrombospondin was inhibited by both specific polyclonal and monoclonal antibodies to this molecule, and not by nonspecific IgG. The use of monoclonal antibodies directed at various epitopes on the thrombospondin molecule was intended to provide some insight as to which domain of this large and complicated molecule was responsible for its growth stimulatory properties. Thus, the lack of discrimination in the inhibitory properties of all three monoclonal antibodies was a surprise, but not unexpected in view of similar lack of discrimination of several different monoclonal antibodies in their ability to inhibit smooth muscle cell proliferation (22) and, cell attachment and spreading (15). It is unclear if this implies that stimulation of proliferation by thrombospondin requires interaction at all these domains of the thrombospondin molecule, or that antibody binding to any domain prevents proper binding of thrombospondin to the cell surface, or both.

These effects on cell proliferation were unaccompanied by any significant effects on protein synthesis, thus suggesting that the growth promoting properties are mediated directly and not via 
alterations in overall bulk protein and matrix synthesis. The data however cannot rule out qualitative or compositional changes in secreted and cell-associated matrix production which could indirectly affect cell proliferation. Thus whatever role that thrombospondin plays in wound healing and repair processes is not mediated by increased bulk matrix synthesis per cell, although it could still stimulate matrix production by increasing the number of matrix producing cells via its growth promoting properties. The ability of certain cytokines to regulate thrombospondin synthesis (32, 33) is consistent with this role for thrombospondin in promoting fibrosis, especially at inflammatory sites where increased cytokine secretion is expected.

Acknowledomente: This work was supported in part by National Institutes of Health grants HL28737, HL31963, HL39925 and DK38149. Part of this work was performed during the tenure of an Established Investigatorship (SHP) from the American Heart Association.

\section{REFERENCES}

1. Baenziger, N.L., Brodie, G.N. and Majerus, P.W. (1972) J. Biol. Chem. 247, 2723-2731.

2. Lawler, J.W., Slayter, H.S. and Coligan, J.E. (1978) J. Biol. Chem. 253, 8609-8616.

3. Margossian, S.S., Lawler, J.W. and Slayter, H.S. (1981) J. Biol. Chem. 256, 7495-7500.

4. Leung, L.L. (1984) J. Clin. Invest. 74, 1764-1772.

5. Jaffe, E.A., Ruggiero, J.T., Leung, L.L.K, Doyle, M.J., McKeown-Longo, P.J. and Mosher, D.F. (1983) Proc. Natl. Acad. Sci. USA 80, 998-1002.

6. Majack, R.A., Cook, S.C. and Bornstein, P. (1985) J. Cell Biol. 101, 1059-1070.

7. Wight, T., Raugi, G.J., Mumby, S.M. and Bornstein, P. (1985) J. Histochem. Cytochem. 33, 295-302.

8. Raugi, G.J., Olerud, J.E. and Gown, A.M. (1987) J. Invest. Dermatol. 89, 551-554.

9. McPherson, J., Sage, H. and Bornstein, P. (1981) J. Biol. Chem. 256, 11330-11336.

10. Mosher, D.F., Doyle, M.J. and Jaffe, E.A. (1982) J. Cell Biol. 93, 343-348.

11. Sage, H., Farin, F.H., Striker, G.E. and Fisher, A.B. (1983) Biochemistry 22, 2148-2155.

12. Jaffe, E.A., Ruggiero, J.T. and Falcone, D.J. (1985) Blood 65, 79-84.

13. Wikner, N.E., Dixit, V.M., Frazier, W.A. and Clark, R.A.F. (1987) J. Invest. Dermatol. 88, 207-211.

14. Raugi, G.J. and Lovett, D.H. (1987) Am. J. Pathol. 129, 364-372.

15. Varani, J., Dixit, V.M., Fligiel, S.E.G., McKeever, P.E. and Carey, T.E. (1986) Exp. Cell Res. 167, 376-390.

16. Tuszynski, G.P., Rothman, V., Murphy, A., Siegler, K., Smith, L., Smith, S., Karczewaki, J. and Knudsen, K.A. (1987) Science 236, 1570-1573.

17. Taraboletti, G., Roberts, D.D. and Liotta, L.A. (1987) J. Cell Biol. 105, 2409-2415.

18. Varani, J., Nickoloff, B.J., Riser, B.L., Mitra, R.S., O'Rourke, K. and Dixit, V.M. (1988) J. Clin. Invest. 81, 1537-1544.

19. Nickoloff, B.J., Mitra, R.S., Riser, B.L., Dixit, V.M. and Varani, J. (1988) Am. J. Pathol. 132, 543-551.

20. Majack, R.A., Cook, S.C. and Bornstein, P. (1986) Proc. Natl. Acad. Sci. USA 83, 9050-9054.

21. Scott-Burden, T., Resink, T.J., Baur, U., Bürgin, M. and Buhler, F.R. (1988) Biochem. Biophys. Res. Commun. 150, 278-286.

22. Majack, R.A., Goodman, L.V. and Dixit, V.M. (1988) J. Cell Biol. 106, 415-422.

23. Mumby, S.M., Abbott-Brown, D., Raugi, G.J. and Bornstein, P. (1984) J. Cell. Physiol. 120, 280-288.

24. Phan, S.H., Thrall, R.S. and Williams, C. (1981) Am. Rev. Resp. Dis. 124, 428-434.

25. Dixit, V.M., Grant, G.A., Santoro, S.A. and Frazier, W.A. (1984) J. Biol. Chem. 259, 10100-10105.

26. Galvin, N.J., Dixit, V.M., O'Rourke. K.M., Santoro, S.A., Grant, G.A. and Frazier, W.A. (1985) J. Cell Biol. 101, 1434-1441.

27. Dixit, V.M., Haverstick, D.M., O'Rourke, K.M., Hennessy, S.W., Grant, G.A., Santoro, S.A. and Frazier, W.A. (1985) Proc. Natl. Acad. Sci. USA 82, 3472-3476. 
28. Dixit, V.M., Haverstick, D.M., O’Rourke, K.M., Hennessy, S.W., Grant, G.A., Santoro, S.A. and Frazier, W.A. (1985) Biochemistry 24, 4270-4278.

29. Phan, S.H., McGarry, B.M., Loeffler, K.M., Kunkel, S.L. (1987) J. Leukocyte Biol. 42, 106-113.

30. Phan, S.H., McGarry, B.M., Loeffler, K.M., Kunkel, S.L. (1988) Biochemistry 27, 2846-2853.

31. McKeown-Longo, P.J., Hanning, R. and Mosher, D.F. (1984) J. Cell Biol. 98, 22-28.

32. Asch, A.S., Leung, L.L.K., Shapiro, J. and Nachman, R.L. (1986) Proc. Natl. Acad. Sci. USA 83, 2904-2908.

33. Majack, R.A., Milbrandt, J. and Dixit, V.M. (1987) J. Biol. Chem. 262, 8821-8825. 